\title{
Ketamine and depression: a narrative review
}

This article was published in the following Dove Press journal:

Drug Design, Development and Therapy

\author{
Alexandrine Corriger ${ }^{1,2}$ \\ Gisèle Pickering (D) ${ }^{1,2}$ \\ 'Neuro-Dol Laboratory Inserm I I07, \\ Clermont Auvergne University, \\ Clermont-Ferrand, France; ${ }^{2}$ Clinical \\ Pharmacology Department CPC/CIC \\ Inserm 1405, Clermont-Ferrand \\ University Hospital, Clermont-Ferrand, \\ France
}

\begin{abstract}
Depression is the third leading cause of disability in the world. Depressive symptoms may be reduced within several weeks after the start of conventional antidepressants, but treatment resistance concerns one-third of patients who fail to achieve recovery. Over the last 20 years, ketamine, an antagonist of the N-methyl-D-aspartate receptor, has been described to have antidepressant properties. A literature review was conducted through an exhaustive electronic search. It was restricted to Cochrane reviews, meta-analyses, and randomized controlled trials (RCTs) of ketamine for major depressive disorder and/or bipolar disorder. This review included two Cochrane reviews, 14 meta-analyses and 15 trials. Ketamine was studied versus placebo, versus other comparators and as an anesthetic adjuvant before electroconvulsive therapy. In 14 publications, ketamine provided a rapid antidepressant effect with a maximum efficacy reached at 24 hrs. Its effect lasted for 1-2 weeks after infusion, but a longer-term effect is little reported. Ketamine does not seem to improve depressive symptoms at the end of electroconvulsive sessions. Safety and tolerability profiles with ketamine at low single dose are generally good in depressed patients. However, there is a lack of data concerning ketamine with repeated administration at higher doses. The clinical use of ketamine is increasing. Intranasal (S)-ketamine has recently been approved for depression by the Food and Drug Administration. It could be a promising treatment in depressed patients with suicidal ideation. Collectively, the level of proof of efficacy remains low and more RCTs are needed to explore efficacy and safety issues of ketamine in depression.
\end{abstract}

Keywords: ketamine, depression, major depressive disorder, bipolar depression, suicide, efficacy

\section{Introduction}

Depression, a major public health problem, is the third leading cause of disability in the world. Depression is different from usual mood fluctuations and common depressive episodes. ${ }^{1}$ It affects approximately 350 million individuals worldwide ${ }^{2}$ and results in personal suffering and economic loss. ${ }^{3}$ Low mood, sadness, feelings of guilt, lack of motivation, anxiety, and suicidal thoughts are common symptoms shown in depression. A distinction can be made between depression in people who have or do not have a history of manic episodes. Both types of depression can be chronic with relapses, especially if they go untreated. ${ }^{1}$

Major depressive disorder (MDD), also known as unipolar depression, is estimated to $28.2 \%$ over a lifetime in the general population. ${ }^{4}$ Bipolar disorder of type I (with mania) and type II (with hypomania) is considered as an episodic and debilitating condition, with a lifetime prevalence of $2.4 \% .^{5}$ Depressive symptoms (bipolar depression or BD) predominate over manic/hypomanic symptoms during the longitudinal course of both bipolar I and II disorder. ${ }^{6,7}$
Correspondence: Gisèle Pickering Clinical Pharmacology Department CPC/ $\mathrm{CIC}$ Inserm I405, Clermont-Ferrand University Hospital, Bâtiment 3C, 58 Rue Montalembert, Clermont-Ferrand Cedex I F-63003, France

Tel +334731784I6

Fax +33473178412

Email gisele.pickering@uca.fr 
A reduction in depressive symptoms is observed within several weeks after the start of treatment after conventional antidepressants but remission with this therapy remains insufficient after several weeks and one-third of patients fail to achieve functional recovery despite multimodality treatment interventions. ${ }^{8}$ The pathophysiology of depression relies mainly on monoamine deficiency, ${ }^{9}$ but an increase of glutamate has also been suggested in animals ${ }^{10}$ and humans, ${ }^{11,12} \mathrm{~N}$-methyl-D-aspartate receptors (NMDAR) are hence at the heart of the pathophysiology of depression. In that context, the non-competitive voltage-dependent NMDAR antagonist ketamine is very interesting with its specific and rapid action on the NMDAR and on a myriad of other receptors.

In patients with MDD or $\mathrm{BD}$, abnormalities in neurotransmission and neuronal plasticity may lead to aberrant functional connectivity patterns within large brain networks. ${ }^{13}$ Network dysfunction in association with altered brain levels of glutamate and gamma-aminobutyric acid (GABA) have been identified in both animal and human studies of depression. ${ }^{13,14}$

Increased synaptic glutamate concentration has been described in MDD, ${ }^{15-17}$ a phenomenon linked to complex molecular changes such as lower expression $\alpha$-amino-3hydroxy-5-méthylisoazol-4-propionate receptor (AMPAR), impaired mechanistic target of rapamycin (mTOR) complex signaling pathway, and lower level of brain-derived neurotrophic factor (BDNF) ${ }^{18}$ that may lead to neuronal atrophy (dendritic retraction, decrease in dendritic tree structure and number of synapses). ${ }^{19}$

Ketamine has been shown to have an antidepressant effect in animal models with increases of AMPAR activity, levels of phosphorylated mTOR, and expression of BDNF. ${ }^{18}$ Over the last 20 years, ketamine has received great attention for its rapid antidepressant property after a single sub-anesthetic dose in individuals with (treatment-resistant) MDD or $\mathrm{BD}^{20-23}$ This narrative review aims to explore in the literature the efficacy of ketamine when used in MDD and BD.

\section{Methods}

A literature review was conducted through an exhaustive electronic search of Medline, PubMed, Google Scholar, and Cochrane databases. Key words such as "ketamine depression", "major depressive disorder", or "bipolar disorder" were used without limitation in language or date of publication. The last search was conducted in May 2019. It was restricted to meta-analyses, Cochrane reviews, parallel-group and cross-over randomized controlled trials
(RCTs), comparing ketamine versus placebo (saline infusion) or active control for MDD and/or BD. This search included studies concerning ketamine as a pharmacological drug to treat depression and as an anesthetic adjuvant before electroconvulsive therapy (ECT). Inclusion criteria were established prior to article review:

- Design: Cochrane reviews, meta-analyses, double- or single-blind, cross-over or parallel, versus placebo or active control RCTs;

- Etiology: (treatment-resistant) MDD and BD;

- Outcomes (primary or secondary): ketamine efficacy defined by a significant change in depression severity score before and after treatment, assessed by validated depression rating scales (MontgomeryAsberg Depression Rating Scale (MADRS); ${ }^{24}$ Hamilton Depression Rating Scale (HDRS); ${ }^{25,26}$ Beck Depression Inventory (BDI)); ${ }^{27}$ response rate generally defined by a reduction of at least $50 \%$ compared to baseline on the validated scales (MADRS, HDRS, or BDI); remission rate defined, according to studies, by a score of $<7$ on the HDRS$17,{ }^{28}$ or $<8$ for all the other longer versions of the HDRS, or $<11$ on the MADRS; ${ }^{29}$ suicidal ideation assessed by validated scales (MADRS-suicidal ideation scores, Quick Inventory of Depressive Symptomatology - Self-Report suicidality item, Beck Scale for suicidal ideation).

\section{Results}

A total of 2861 items were identified after database research and 417 were eligible for this review. After having discarded duplicates, screened abstracts, and removed excluded publications (Figure 1), 31 articles were included in this review: 2 Cochrane reviews, 14 meta-analyses, and 15 RCTs that had not been included in the Cochrane reviews and meta-analyses. Studies included in Cochrane reviews or in meta-analyses were not analyzed separately. In the selected literature, ketamine was used:

1. Alone as a pharmacological drug versus placebo, or in combination (one study) with escitalopram to treat MDD and BD versus placebo,

2. Alone as a pharmacological drug to treat MDD and $\mathrm{BD}$ versus other comparators,

3. As a pre-ECT anesthetic adjuvant alone or in combination with thiopental or propofol versus placebo or active control. 


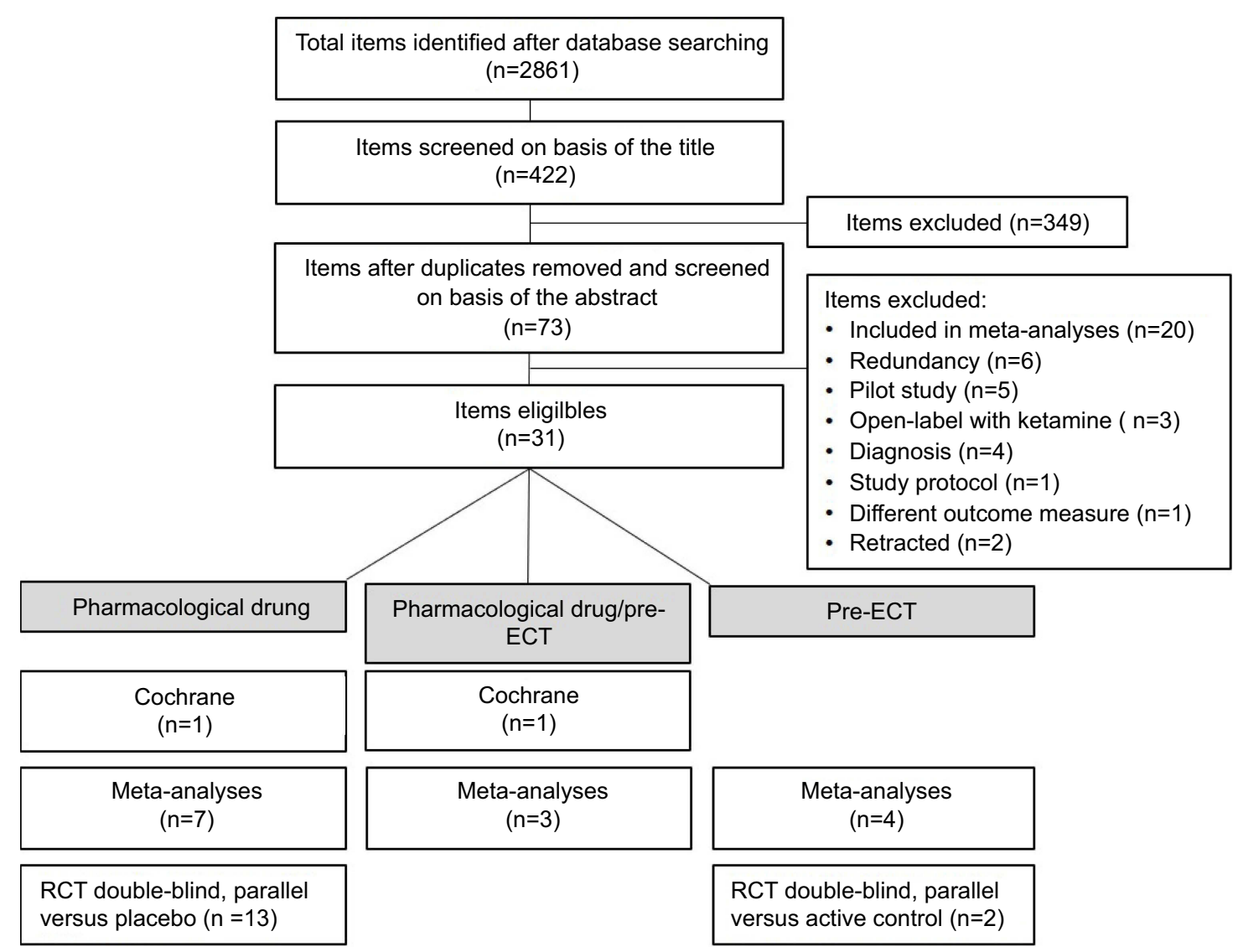

Figure I Flowchart of the literature review process.

Abbreviations: ECT, electroconvulsive therapy; RCT, randomized controlled trial.

Two Cochrane reviews have been published, McCloud et al, 2015 in $\mathrm{BD}^{30}$ and Caddy et al, 2015 in MDD and $\mathrm{BD} .{ }^{31} \mathrm{~A}$ total of 14 meta-analyses (1-16 studies per metaanalysis, $\mathrm{n}=35-928$ ) in MDD and BD were included in this review. ${ }^{32-45}$ Among RCTs included in these meta-analyses, 7 RCTs were also included in the Cochrane reviews. All the articles included in the Cochrane reviews and in the metaanalyses are listed in Table 1. An additional number of 15 double-blind parallel RCTs versus placebo ${ }^{46-56}$ or versus active control ${ }^{57,58}$ in MDD patients have been published since the publication of the Cochrane reviews and the metaanalyses (Table 2).

\section{Ketamine efficacy, response, and remission \\ Ketamine versus placebo}

Ketamine efficacy, defined by a significant difference in depression severity score before and after treatment, assessed by validated depression rating scales, was shown in favor of ketamine over placebo at $40 \mathrm{mins},{ }^{51,53,55}$ 60-80 mins, ${ }^{34,53} 2 \mathrm{hrs},{ }^{53,54,56} 4 \mathrm{hrs},{ }^{49,51,52,54,56} 1$ day, ${ }^{30,33,49,50,52-54} 2$ days, ${ }^{33,50,53,56} 3$ days, ${ }^{30,33,51,53,54,56}$ 4 days, ${ }^{33,53} 5$ days, ${ }^{53} 6$ days, ${ }^{53} 1$ week, $, 33,50,51,53,54$ 2 weeks, ${ }^{32,48,50,51,53,54} 3$ weeks, ${ }^{51} 4$ weeks, ${ }^{47,48,53}$ and 6 weeks. ${ }^{48}$ However, some studies did not find a difference at $40 \mathrm{mins},{ }^{52} 60-80 \mathrm{mins},{ }^{52,54,55} 2 \mathrm{hrs},{ }^{52,55} 4 \mathrm{hrs},{ }^{34,55} 1$ day, ${ }^{47} 1$ week, ${ }^{30,46,47} 2$ weeks, ${ }^{30,33,34,46,47} 3$ weeks, ${ }^{46,47,54}$ and 4 weeks. ${ }^{49,54}$ There were more responders (defined by a reduction of at least $50 \%$ compared to baseline on the validated scales) with ketamine versus placebo at 40 mins,${ }^{55} 80$ mins, ${ }^{55} 4 \mathrm{hrs},{ }^{52} 1$ day, ${ }^{30,52,53,56} 3$ days,${ }^{30}$ 4 days, ${ }^{53} 2$ weeks, ${ }^{32} 3$ weeks, ${ }^{51}$ and 6 weeks. ${ }^{48}$ There was no difference at $2 \mathrm{hrs},{ }^{55} 4 \mathrm{hrs},{ }^{55} 1$ day ${ }^{47} 1$ week, ${ }^{30}$ 2 weeks, ${ }^{30} 3$ weeks, ${ }^{46} 4$ weeks, ${ }^{47}$ and 3 months. ${ }^{46}$ There was no available data for ketamine efficacy at 4,6 , and 8 weeks in a meta-analysis. ${ }^{32}$ Concerning remitters rate, only one study showed a significant difference in favor of ketamine at 3 weeks of treatment, ${ }^{51}$ otherwise there was no evidence at any time point for this endpoint. ${ }^{30,46,48}$

A RCT observed that ketamine combined with escitalopram brought a significant difference in depression severity score at 2 hrs, 4 hrs, 1 day, 3 days, 1 week, and 


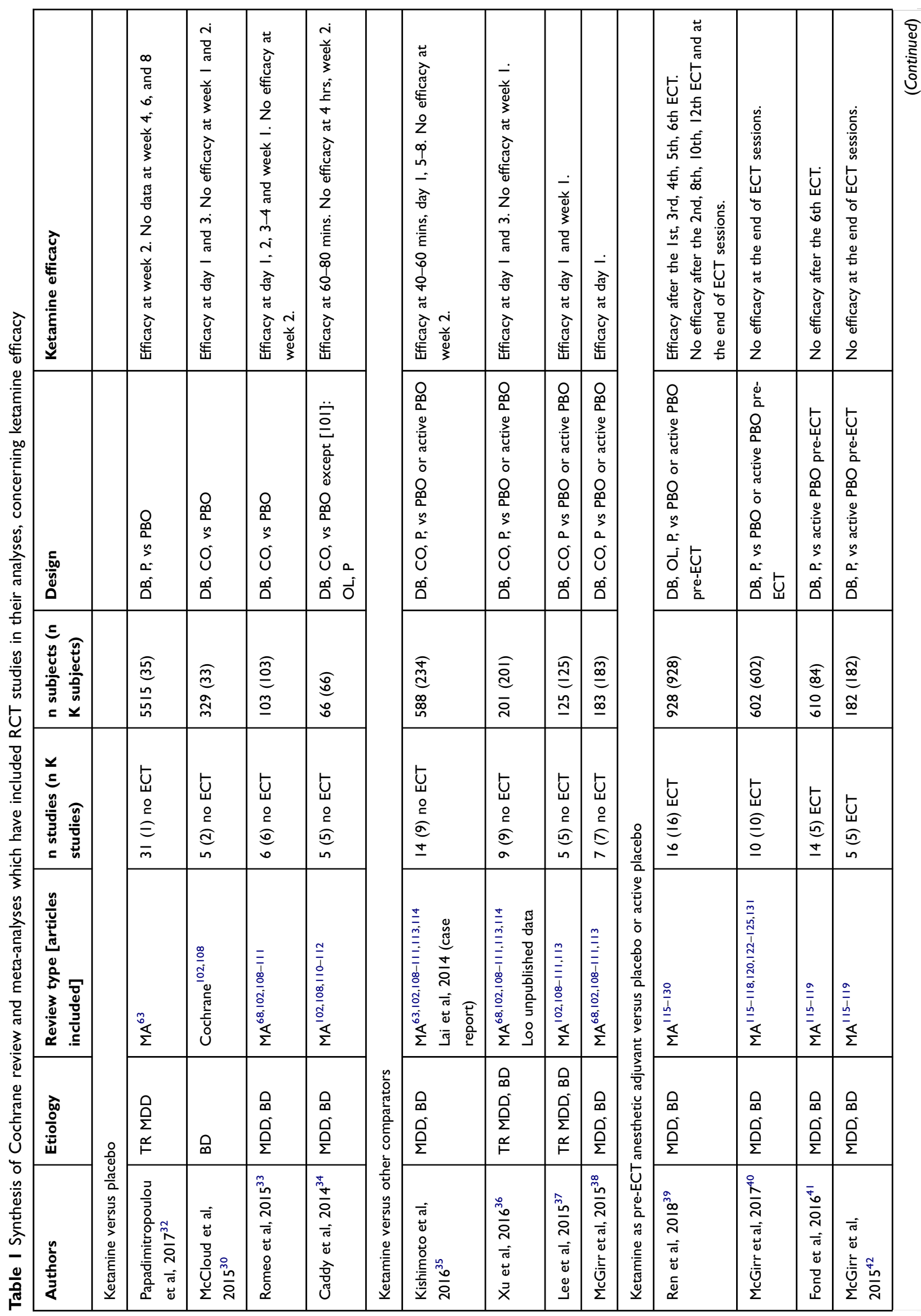




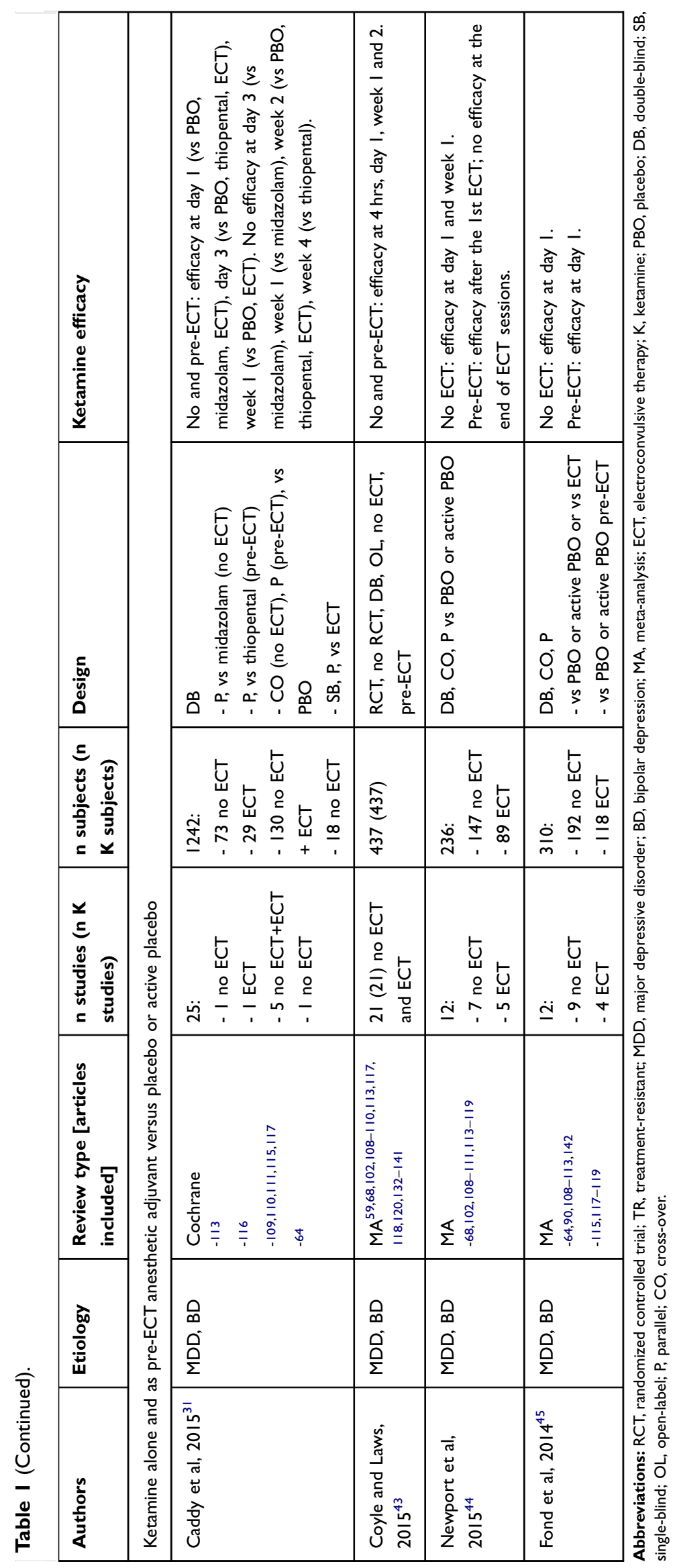




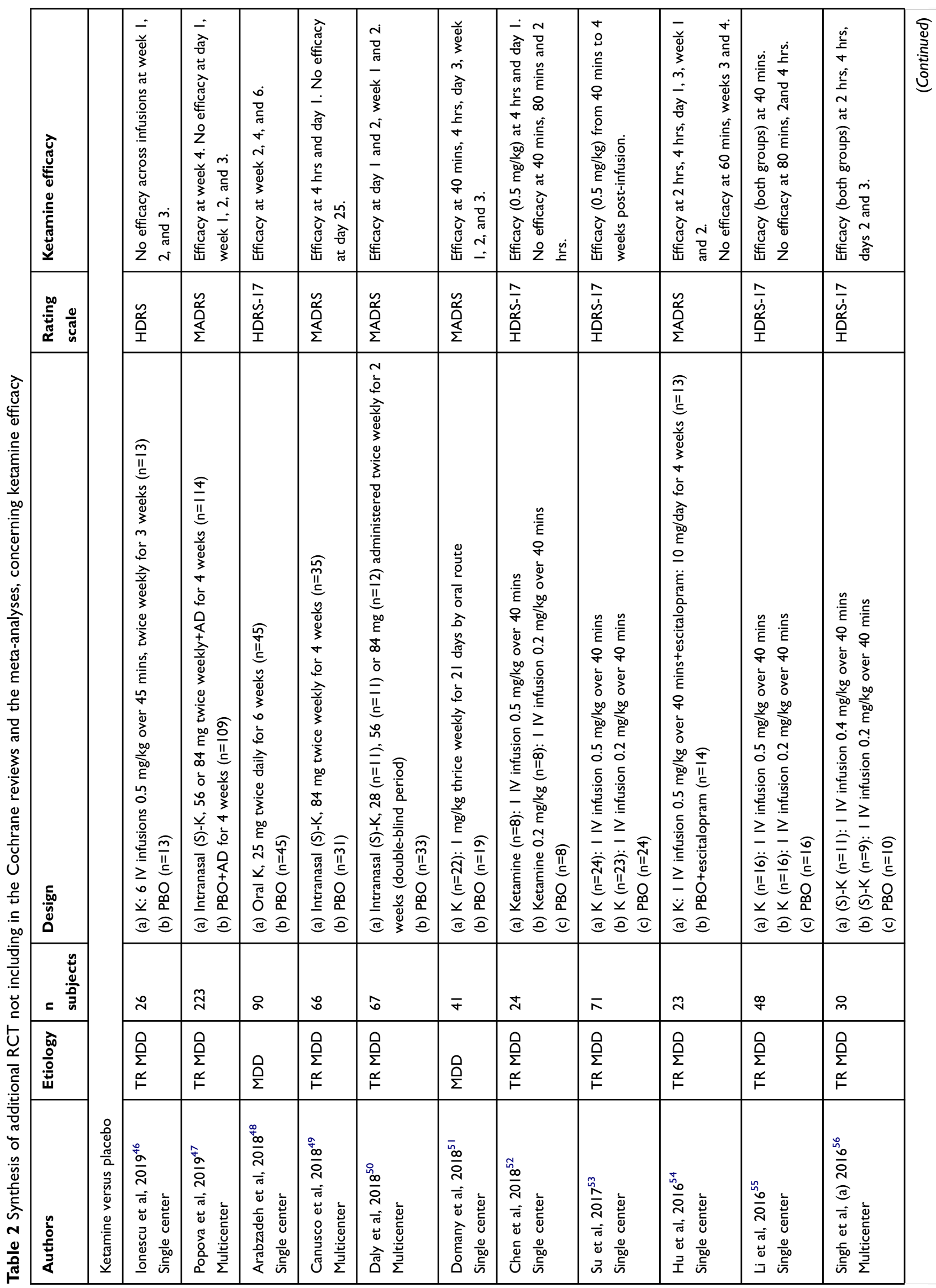






2 weeks with no difference at 60 mins, 3 weeks, and 4 weeks versus placebo combined with escitalopram. ${ }^{54}$ Responders and remitters rates were significantly higher with ketamine at 4 weeks only (Figure 2A). ${ }^{54}$

\section{Ketamine versus other comparators}

Versus both placebo and active placebo

Meta-analyses found that ketamine efficacy was better than placebo and active placebo at 40/60 mins, ${ }^{35} 1$ day, ${ }^{35-38,44,45}$ 3 days, ${ }^{36} 5$ days, ${ }^{35}$ and 1 week. ${ }^{35,37,44}$ A few meta-analyses have found no efficacy at 1 week $^{36}$ and 2 weeks. ${ }^{35}$ Ketamine showed a higher response rate at $4 \mathrm{hrs},{ }^{35,44} 1$ day, ${ }^{36,38,44}$ 2-3 days, ${ }^{36,38,44} 1$ week, ${ }^{36,38}$ and 2 weeks ${ }^{44}$ compared with the control group. Remission symptoms with ketamine were observed at 80 mins, ${ }^{35,44} 1$ day, ${ }^{35,36,38,44} 3-5$ days, ${ }^{35,36,38,44}$ and at 1 week $^{36,38}$ but no longer at 2 weeks. ${ }^{44}$

\section{Versus midazolam}

A Cochrane review by Caddy et al showed that ketamine was more effective than midazolam at 1 day but no longer at 3 days or at 1 week. ${ }^{31}$ Ketamine was better than midazolam in response rate at 1 day, 3 days, and 1 week. ${ }^{31} \mathrm{~A}$ significant difference in remission in favor of ketamine was found at 1 day. There was no difference at 3 days and at 1 week. ${ }^{31}$

\section{Versus ECT}

A Cochrane review ${ }^{31}$ compared ketamine, as a pharmacological agent, versus ECT in MDD patients. Ketamine was more effective than ECT at 1 day, 3 days, and 1 week but no longer at 2 weeks. ${ }^{31}$ Response rate was more important with ketamine than ECT at 1 day and 3 days but no longer at 1 and 2 weeks. ${ }^{31}$ There was no difference in remission at any time point (Figure 2A). ${ }^{31}$

\section{Ketamine as pre-ECT anesthetic adjuvant}

Ketamine effect has been studied as pre-ECT anesthetic adjuvant alone or in combination with either thiopental, propofol, or methohexital (Figure 2B).

Ketamine as an anesthetic adjuvant alone versus active placebo pre-ECT

Versus thiopental. Ketamine was more effective than thiopental at 3 days but no longer at 2 weeks or at 4 weeks. ${ }^{31}$ There was no difference between the two groups in term of response at any time points and there was no remitter at any time point in each group. ${ }^{31}$

Versus methohexital. In one parallel RCT versus methohexital, ketamine was administered before three 

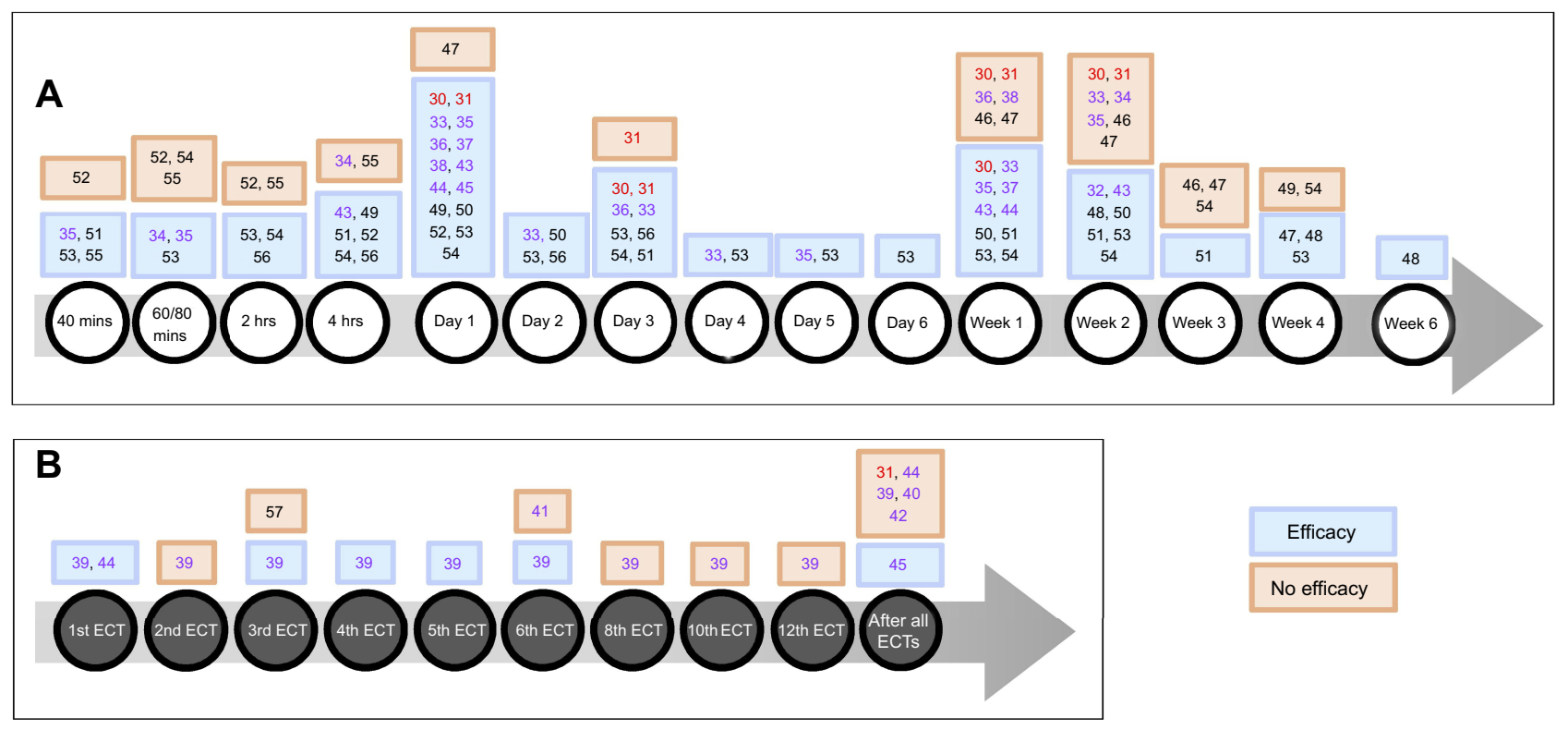

Figure 2 (A) Ketamine efficacy with time (versus placebo or other comparators). (B) Ketamine efficacy with the number of electroconvulsive therapies (ECT) (ketamine given as an anesthetic adjuvant pre-ECT).

Notes: Numbers represent references. Bold red: Cochrane review; bold purple: meta-analyses; others: randomized controlled trials.

consecutive ECT sessions. ${ }^{57}$ Even though depression scores improved after ECT sessions, there was no significant difference in ketamine efficacy between the groups. There was no data for response and remission. ${ }^{57}$

Versus propofol. In another parallel RCT versus propofol, ketamine was administrated with a frequency of two or three sessions per week, before each ECT sessions. ${ }^{58}$ This study showed faster improvement of depressive symptoms with ketamine (response rate was attained after two ECT with ketamine versus four ECT with propofol), and fewer treatments to achieve remission (four ECT in the ketamine arm versus seven ECT in the propofol arm). ${ }^{58}$

Ketamine as an anesthetic adjuvant alone and/or in combination with another pre-ECT anesthetic drug versus placebo or active placebo

Meta-analyses showed that ketamine efficacy was observed at day $1^{45}$ or after the $1 \mathrm{st},{ }^{39,44} 3 \mathrm{rd},{ }^{39} 4$ th,${ }^{39} 5$ th, ${ }^{39}$ and 6 th ECT sessions, ${ }^{39}$ but with no difference after the $2 \mathrm{nd},{ }^{39}$ 3rd, ${ }^{57} 6$ th,${ }^{41} 8$ th,,${ }^{39} 10$ th, ${ }^{39}$ and 12 th $\mathrm{ECT}^{39}$ or at the end of the complete course of ECT sessions. ${ }^{39,40,42,44}$ There was no difference in terms of response ${ }^{39-42,44}$ and remission. ${ }^{39,40,42,44}$

\section{Ketamine administration}

Ketamine efficacy was observed after only one intravenous (IV) infusion of $0.5 \mathrm{mg} / \mathrm{kg}$ over 40 mins versus placebo $^{30,31}$ or midazolam. ${ }^{31} \mathrm{~A}$ single IV infusion of either $0.2 \mathrm{mg} / \mathrm{kg}$ or $0.5 \mathrm{mg} / \mathrm{kg}$ of ketamine compared with placebo was used in three RCTs and ketamine efficacy was observed with a dose of $0.5 \mathrm{mg} / \mathrm{kg}^{52,53}$ but not with the $0.2 \mathrm{mg} / \mathrm{kg}$ dose. ${ }^{53}$ Another study showed that both ketamine dosages showed higher efficacy than placebo. ${ }^{55}$ One study used a single IV infusion of (S)-ketamine with two doses of 0.2 and $0.4 \mathrm{mg} /$ $\mathrm{kg}$ in each group. An improvement in both (S)-ketamine groups was observed. ${ }^{56}$ One study performed a single IV infusion of $0.5 \mathrm{mg} / \mathrm{kg}$ of ketamine in combination with escitalopram (10 mg per day for 4 weeks) versus placebo and escitalopram and ketamine efficacy was observed until 2 weeks. ${ }^{54}$

Ketamine was administered in repeated doses by IV route in one study with a total of six infusions of $0.5 \mathrm{mg} / \mathrm{kg}$ twice weekly for 3 weeks but with no significant difference in favor of ketamine versus placebo across infusions. ${ }^{46}$ In a Cochrane review, ${ }^{31}$ ketamine was administered by three IV infusions of $0.5 \mathrm{mg} / \mathrm{kg}$ over $45 \mathrm{mins}$ every 48 hrs and compared with three ECT sessions every $48 \mathrm{hrs}$ (with $2-3 \mathrm{mg} / \mathrm{kg}$ of thiopental pre-ECT) and efficacy was observed until 1 week.

Repeated oral racemic ketamine administration brought efficacy in two studies, with a dose of $25 \mathrm{mg}$ twice daily for 6 weeks $^{48}$ or $1 \mathrm{mg} / \mathrm{kg}$ thrice weekly for 3 weeks ${ }^{51}$ versus placebo. 
Intranasal (S)-ketamine was used in three recent RCT with a dose of $84 \mathrm{mg}$ twice weekly for 4 weeks in addition to comprehensive standard-of-care treatment ${ }^{49}$ or with an oral antidepressant ${ }^{47}$ and from 28 to $84 \mathrm{mg}$ administered twice weekly for 2 weeks. ${ }^{50}$

Caddy et $\mathrm{al}^{31}$ compared ketamine $(1-2 \mathrm{mg} / \mathrm{kg})$ versus thiopental $(2-3 \mathrm{mg} / \mathrm{kg})$ in MDD patients, for pre-ECT anesthesia. A total of six ECT sessions were performed in each group, with three sessions per week and ketamine was more efficient than thiopental up to 3 days after ECT sessions. In meta-analyses, ketamine was reported with a dose between 0.3 and $1-2 \mathrm{mg} / \mathrm{kg}$ pre-ECT as an anesthetic agent alone or associated with another anesthetic agent (thiopental, propofol) with limited evidence in favor of ketamine. In one RCT, ketamine was administered with a dose of $1-2 \mathrm{mg} / \mathrm{kg}$ versus $1-2 \mathrm{mg}$ of methohexital, before three consecutive ECT sessions ${ }^{57}$ with no difference between both groups. Another study used a dose of $0.75 \mathrm{mg} / \mathrm{kg}$ of ketamine versus $1 \mathrm{mg} / \mathrm{kg}$ of propofol before ECT sessions with a frequency of two or three sessions per week, ${ }^{58}$ with a faster improvement of depressive symptoms with ketamine. Overall, depression was not improved significantly when ketamine was associated with ECT.

\section{Ketamine and suicide}

Several RCTs have assessed suicidal ideation in depressed patients. ${ }^{46,49,54,59-61}$ In treatment-resistant MDD or BD patients, ketamine provided a reduction in MADRS-suicidal ideation scores ${ }^{59}$ versus placebo and a reduction in explicit suicidal cognition versus midazolam ${ }^{60} 1$ day after a single infusion of $0.5 \mathrm{mg} / \mathrm{kg}$ over 40 mins. A single dose of ketamine combined with escitalopram significantly reduced Quick Inventory of Depressive Symptomatology Self-Report suicidality item versus placebo until 3 days post-infusion. ${ }^{54}$ Significantly greater improvement was also observed with intranasal S-ketamine on the MADRS-suicidal thoughts item score at $4 \mathrm{hrs}$, but not at $24 \mathrm{hrs}$ or at day $25 .^{49}$

However, one RCT did not find a difference 1 day following treatment in Beck Scale for suicidal ideation score between ketamine $0.5 \mathrm{mg} / \mathrm{kg}$ and midazolam, even though a significant difference emerged at 2 days. ${ }^{61}$ In this study, the MADRS-suicidal ideation score was lower in ketamine compared to midazolam at day $1{ }^{61}$ In a recent study, ketamine did not have significantly better effect on suicidal ideation than placebo after six ketamine infusions $(0.5 \mathrm{mg} / \mathrm{kg}$ over $45 \mathrm{mins})$ over 3 weeks. $^{46}$

\section{Discussion}

\section{Ketamine as a pharmacological drug}

This review shows that ketamine provides a rapid and robust antidepressant effect with an onset of 40 mins after a single IV infusion in MDD and BD with a maximum efficacy at 24-hr post-infusion in 14 publications. $^{30,31,33,35-38,44,45,49,50,52-54}$ This effect on depression is however transient and disappears 1-2 weeks post-infusion. There is limited evidence for ketamine efficacy in depressive patients (over placebo) after 1 week and even less after 2 weeks. ${ }^{31}$ This limited evidence in favor of ketamine could be explained by differences in the etiology and subtype of patients, ketamine dosage, mode of administration, and pharmacokinetics.

\section{Ketamine short-term efficacy variability Subtypes of patients}

Ketamine could act differently according to specific subtypes of patients. Ketamine effects were modulated by depression severity at baseline and were not effective in patients with mild depression. In patients with greater depression severity at baseline, the $0.5 \mathrm{mg} / \mathrm{kg}$ dose increasingly separates from placebo and $0.2 \mathrm{mg} / \mathrm{kg}$ dose. ${ }^{53}$ The antidepressant effect of ketamine may also vary according to the etiology. A meta-analysis showed that treatment effect is moderately attenuated for patients with MDD at 7 days. In both trials with BD, treatment effect dissipated by days $4-7 .{ }^{36}$ Moreover, there are preliminary results to indicate that ketamine may have superior antidepressant properties among treatment-resistant patients with an anxious form of BD as opposed to nonanxious BD. In this study, the anxious depressed group did not show a clear antidepressant response disadvantage over the non-anxious group. ${ }^{62}$

\section{Ketamine administration}

Most studies used IV route and a single dose of ketamine (mostly at $0.5 \mathrm{mg} / \mathrm{kg}$ over $40-45 \mathrm{mins}$ ) was enough to improve depression state when ketamine was used alone or in combination with thiopental or propofol. A dose-related antidepressant effect was suggested as $0.2 \mathrm{mg} / \mathrm{kg}$ but was not efficacious. ${ }^{53}$ Ketamine antidepressant efficacy could also vary with the number of IV infusion or mode of administration. Several studies have examined whether repeated doses of $0.5 \mathrm{mg} / \mathrm{kg}$ by IV route could have a better antidepressant effect and might extend the duration of antidepressant effect compared to a single dose. 
Overall, the effect stopped after discontinuation of the treatment (or was not assessed). One study did not show a significant difference between ketamine and placebo groups with depression rating scale score across infusions (or with response or remission rates). ${ }^{46}$ Another study showed significant difference in MADRS scores at day 15 and day $29 .{ }^{63}$ The last study included in this review showed benefice 72 -hr post-infusion but no longer at oneweek post-treatment. ${ }^{64}$

Ketamine bioavailability by oral route varies from $17 \%$ with $0.5 \mathrm{mg} / \mathrm{kg}^{65,66}$ to $30 \%$ with $50 \mathrm{mg}^{67}$ of racemic ketamine, because of an extensive first-pass metabolism. Repeated administration of ketamine by oral route was used in three studies and provide efficacy during all the treatment intake ( 3 weeks ${ }^{51}$ and 6 weeks). ${ }^{48}$ However, no assessment was done after discontinuation of oral ketamine.

Racemic ketamine bioavailability by intranasal route is higher than oral route and reaches $45 \%$ with a dose of 25 mg. ${ }^{67}$ Several RCTs were focused on the intranasal route and one study ${ }^{68}$ was included in five meta-analyses. ${ }^{33,36,38,43,45}$ These RCTs provide the first controlled evidence for the rapid antidepressant effects of intranasal ketamine, ${ }^{47,49,50,68}$ including suicidal ideation improvement. ${ }^{50}$ (S)-ketamine efficacy was observed during the 2 weeks of treatment with adjunctive oral antidepressant. ${ }^{50}$ This effect was perceived over the 8-week follow-up phase (without additional (S)-ketamine doses) in participants who remained in the study. ${ }^{50}$ Overall these results are rewarding, especially for suicidal ideation. In March 2019, the US Food and Drug Administration has approved the use of nasal S-ketamine in the first days of treatment-resistant depression, in conjunction with an oral antidepressant.

\section{Ketamine pharmacokinetics - pharmacodynamics}

Concerning ketamine kinetics, once absorbed it is rapidly distributed in the brain and highly perfused tissues, the distribution half-life is short in the range of 2-4 mins, and the elimination half-life $2-4$ hrs. $^{66,69}$ Ketamine's pharmacokinetics could partly explain ketamine shortterm efficacy that may be linked to the immediate effect on NMDAR to offset the dysfunction in glutamatergic neurotransmission. Indeed, postmortem studies have highlighted increased level of glutamate in the frontal cortex from MDD and BD patients, ${ }^{70}$ that could be due to a reduction in the expression of genes for glutamate transporters (such as EAAT-1 and EAAT-2) in the anterior cingulate cortex and dorsolateral prefrontal cortex or of enzymes (L-glutamate-ammonia ligase) that converts glutamate to glutamine in depressed patients. ${ }^{71}$ This glutamate surge which results in synaptogenesis and synaptic potentiation, ${ }^{72,73}$ modulated by AMPAR activation and mTORC1 subsequent involvement has been suggested. ${ }^{14}$

Moreover, preclinical evidence has shown that ketamine displays other mechanisms of action that include $5 \mathrm{HT}_{1 \mathrm{~B}}$ receptor, ${ }^{74}$ 5HT transporter, ${ }^{75}$ increase of 5HT brain level, ${ }^{76,77} \mathrm{GABA}_{\mathrm{A}}$ receptor, ${ }^{78}$ nicotinic acetylcholine receptors, ${ }^{79}$ sigma receptors, especially the subunits $\sigma 1 \mathrm{R}$ and $\sigma 2 \mathrm{R}^{80}$ and hyperpolarization-activated cyclic nucleotide-gated $(\mathrm{HCN})$ channels, in particular the HCN1 channel. ${ }^{81}$ All these actors may play a role in ketamine's rapid and potentially long-term antidepressant effect, but more evidence are needed. Possible ketamine interactions with the opioid system have also been suggested. Pretreatment with naltrexone, an opioid receptor antagonist, diminished ketamine antidepressant effect in MDD patients, suggesting that opioid receptor activation is required for ketamine antidepressant action. ${ }^{82}$ But the sample size was very small $(\mathrm{n}=7)$ and this finding was not observed in rodent model of depression ${ }^{83}$ or in another pilot study. ${ }^{84}$ Other results suggest that combined ketamine with naltrexone might enhance the treatment of comorbid alcohol use disorder. ${ }^{84}$

\section{Ketamine enantiomers and metabolites}

Ketamine enantiomers may also play a role. Due to an asymmetric carbon atom in position $\mathrm{C} 2$, ketamine has a chiral structure composed of two enantiomers: (S)-ketamine and (R)-ketamine. The enantiomer (S)-ketamine is twice as potent as the racemic mixture and four times more potent than the (R)-ketamine enantiomer at NMDAR. ${ }^{85}$ One study compared (S)-ketamine at doses of 0.2 or 0.4 $\mathrm{mg} / \mathrm{kg}$ versus placebo and (S)-ketamine had a rapid onset of robust antidepressant effect in patients with treatmentresistant MDD after a 40-min IV infusion. ${ }^{56}$ The authors suggested that a lower dose may allow for better tolerability than the racemic mixture while maintaining efficacy.

However, although (S)-ketamine has long been considered as an active substance for the action of ketamine, (R)-ketamine has been reported to exhibit longerlasting and more potent antidepressant effects than (S)ketamine in rodent models. ${ }^{72,86-88}$ Administration of equal doses of (R)-ketamine and (S)-ketamine did not yield different levels of these enantiomers in the brain in 
rodents, indicating that increased antidepressant effect of (R)-ketamine is not due to greater brain drug levels. ${ }^{78,87}$ A preclinical study demonstrated that both (R)-ketamine and (S)-ketamine exhibited antidepressant effects at 30 mins and 1 day after administration. At 2 days after administration, (R)-ketamine still exerted a significant antidepressant effect, whereas the effect of (S)-ketamine was no longer observed. ${ }^{87}$ These results suggest that ketamine exerts its antidepressant action not solely via antagonism of NMDAR. BDNF reduction and a decreased phosphorylation of $\operatorname{TrkB}$ were observed in the prefrontal cortex and hippocampus (dentate gyrus, CA3) of depressed mice after social defeat stress, phenomenon attenuated with both ketamine enantiomers. ${ }^{88}$ However, (R)-ketamine induced a more potent beneficial effect on decreased dendritic spine density, BDNF-TrkB signaling and synaptogenesis in those cerebral regions compared with (S)-ketamine. ${ }^{88}$

Zanos et $\mathrm{al}^{78}$ have reported that not only (R)-ketamine has more potent antidepressant effects than (S)-ketamine, but also ketamine metabolite $(2 \mathrm{~S}, 6 \mathrm{~S} ; 2 \mathrm{R}, 6 \mathrm{R})$-hydroxy-norketamine (HNK) is essential and sufficient to exert the antidepressant effects of ketamine, finding also supported by others researches, ${ }^{89}$ even if more studies are needed to confirm this mechanism. In 2019, Phase I clinical studies will study the antidepressant action of (R)-ketamine and $(2 \mathrm{R}, 6 \mathrm{R})-\mathrm{HNK}{ }^{89}$

\section{Ketamine, a long-term efficacy?}

It should be noted that although ketamine has an effect limited to $1-2$ weeks, its antidepressant action can persist for over 2 weeks in some patients, ${ }^{43}$ although plasma levels of ketamine are no longer detectable 1 day after a $0.5 \mathrm{mg} / \mathrm{kg}$ infusion of ketamine. ${ }^{90}$ This may be linked to other active compounds as ketamine is highly metabolized by hepatic cytochromes $\mathrm{P} 450 .{ }^{91}$ The major metabolic pathway concerns the $\mathrm{N}$-demethylation of ketamine to norketamine, an active metabolite in humans. ${ }^{92,93}$ Norketamine is then metabolized to HNK and dehydronorketamine (DHNK) ${ }^{94}$ HNK metabolites are formed by hydroxylation of the cyclohexyl ring of norketamine at several locations, with $(2 \mathrm{R}, 6 \mathrm{R} ; 2 \mathrm{~S}, 6 \mathrm{~S})-\mathrm{HNK}$ and $(2 \mathrm{~S}, 6 \mathrm{R}$; $2 \mathrm{R}, 6 \mathrm{~S})$-HNK being the predominant forms in plasma. ${ }^{95,96}$ The metabolites DHNK and (2R,6R; 2S,6S)-HNK are still detectable 3 days after infusion, ${ }^{90}$ and previous report suggests that metabolites had antidepressant action in animal model. ${ }^{72}$
A case report has suggested that repeated low doses of ketamine can extend its acute efficacy for few months. ${ }^{97}$ But effective methods to prolong initial antidepressant response of ketamine, by targeting glutamatergic system and with lower adverse effect to avoid ketamine abuse and dependence, are still needed. For example, a clinical study (NCT01602185) has assessed dextromethorphan, another NMDAR antagonist, as a ketamine relay to maintain ketamine pain relief in neuropathic pain patients. ${ }^{98}$

\section{Ketamine as pre-ECT anesthetic adjuvant}

Concerning ketamine as an anesthetic adjuvant alone or in combination to augment benefit of ECT, no real improvement was found in term of depressive symptoms or in response and remission rates. Even if ECT itself is an effective treatment for depression with a response rate of $80 \%$ when patients received enough ECT sessions, ${ }^{99}$ repeated ketamine administration, as a monotherapy, has been demonstrated to result in greater improvement than ECT sessions. ${ }^{64}$

Possible reasons that may explain the lack of ketamine efficacy in addition to ECT are that the potential benefit of ketamine has been canceled by ECT even if a meta-analysis showed an enhanced antidepressive effect of ECT in the initial course of treatment. ${ }^{39}$ However, an accelerated effect was found in this meta-analysis ${ }^{39}$ when ketamine was used as an add-on anesthetic with sub-anesthetic doses. The optimal dosing of ketamine for its antidepressant effect is still under investigation, but it is then possible to think that ketamine at anesthetic dose $(1-2 \mathrm{mg} / \mathrm{kg})$ could not have antidepressant effect. Moreover, some studies used barbituric agents (thiopental, propofol) and these molecules do potentiate GABAergic neurons and inhibition of AMPAR. Barbiturics may counteract ketamine inhibition on GABAergic neurons and activation of AMPAR, mechanisms involved in ketamine's antidepressant action. ${ }^{72}$

\section{Ketamine and suicide}

Patients with MDD or BD frequently present hopelessness and can experience suicidal thoughts during a current depressive episode. About $20-25 \%$ of BD patients have reported a history of suicide attempts. ${ }^{5}$ Existing treatment options for these patients include conventional antidepressants, ECT, psychotherapy, lithium, or valproate but some patients are resistant and these treatments have relative sluggishness of therapeutic onset, and hence, the suicidal act may occur during this period. ${ }^{100}$ Ketamine has been 
shown to have rapid effect on suicidal ideation within 2 hrs of administration in patients with treatment-resistant $\mathrm{MDD}^{59,101}$ or in $\mathrm{BD},{ }^{102}$ making it as an attractive therapy for depressed patients with imminent risk of suicide. But some recent studies have found no benefice in the improvement of suicide ideation. ${ }^{46,61}$ A study has shown that ketamine had greater effects in patients with higher level of basal suicidal cognition or with a previous history of suicide attempt. ${ }^{60}$ Ketamine may work most efficaciously in patients at the highest risk of suicide, and this hypothesis could be linked with its efficacy relative to the level of depression because this molecule was not effective in patients with relatively mild depression. ${ }^{53}$ The authors have suggested that ketamine's antidepressant and antisuicidal effects could be the same property because the main antisuicidal effect was reduction in overall (non-suicide related) depressive symptoms. ${ }^{60}$ However, this antisuicidal property has not been assessed in non-depressed patients experiencing suicidal thoughts. Moreover, one study collected patient-level data from four independent, previously published clinical trials and they showed that ketamine exerted an effect on suicidal ideation that was independent of depression and anxiety. ${ }^{103}$

A previous report indicated an increase of quinolinic acid, an NMDAR agonist, in the cerebrospinal fluid (CSF) of suicide attempters. Level of this agonist was correlated with the total scores on Suicide Intent Scale and was associated with higher levels of CSF interleukin- $6 .{ }^{104}$ Changes in glutamatergic neurotransmission could be specifically linked to suicidality and might explain the observed remedial effects of ketamine through NMDAR.

\section{Ketamine safety and toxicity}

Concerning safety and toxicity, only one Cochrane review demonstrated a difference in favor of placebo over ketamine about confusion and emotional blunting in patients with MDD or $\mathrm{BD}^{31}$ However, no conclusive evidence about adverse event was found when ketamine was compared to placebo in $\mathrm{BD} .{ }^{30}$ Studies have shown that safety and tolerability profiles are generally good at low doses and with short-term treatment in depressed patients. The adverse events associated with ketamine usually occur with very high doses that are administered for prolonged periods of time and can be relieved by cessation according to Zhu et al. ${ }^{105} \mathrm{~A}$ recent review has listed all the studies to assess side effects induced by ketamine as a pharmacological drug or pre-ECT in depressive patients. Acute ketamine psychiatric side effects were described in $38 \%$ of studies, whereas psychotomimetic or dissociative side effects were described in $72 \%$ of studies. ${ }^{106}$ An isolated case of a suicide attempt was reported in one study. ${ }^{63}$ No long-term psychotomimetic side effects were reported. ${ }^{106}$

Concerning intranasal (S)-ketamine administration, most adverse events were of mild or moderate severity (dizziness, dissociation, dysgeusia, vertigo, and nausea), were transient and well tolerated. ${ }^{47,49,68}$ A minority of patients with (S)-ketamine experienced adverse events leading to discontinuation of the study drug: $3 / 56$ during the double-blind phase (compared with none receiving placebo) (syncope, headache, dissociative syndrome, and ectopic pregnancy) $;^{50} 8 / 114$ (single events of anxiety, depression, depressive symptoms, panic attack, drug intolerance, feeling drunk, dizziness, headache, vertigo, nausea, road traffic accident, and multiple injuries); 1/109 in the antidepressant plus placebo arm (generalized rash); ${ }^{47} 5 / 35$ (agitation, aggression, unpleasant taste, and ventricular extrasystoles in one participant each, and dizziness, dyspnea, and nausea in one participant); and $1 / 31$ in the placebo group (dissociative disorder and panic attack). ${ }^{49}$

However, there is a lack of data concerning ketamine repeated administration at higher dose in depression. More studies should focus on the risk of serious liver damage, uro-nephrogenic damage or dependence, adverse event previously observed with recreational users. ${ }^{107}$

\section{Conclusion}

Ketamine may provide a rapid, robust, but transient antidepressant effect in MDD and BD. It appears particularly interesting in patients experiencing suicidal thoughts with its rapid effect in suicidal ideation. The benefits of ketamine are transient, up to 1-2 weeks after infusion and its long-term effect is less reported. Acute side effects associated with single-dose use in depression are common, although generally transient and resolve spontaneously. However, acute and long-term efficacy and safety issues must be further explored, and adverse event should be systematically assessed. Further studies are needed to explore the best dose and mode of administration to optimize ketamine antidepressant effect and to clarify its mechanism of action.

\section{Abbreviations}

AMPAR, $\alpha$-amino-3-hydroxy-5-méthylisoazol-4-propionate receptor; BDI, Beck Depression Inventory; BD, bipolar depression; BDNF, brain-derived neurotrophic factor; CSF, cerebrospinal fluid; DHNK, dehydronorketamine; 
ECT, therapy; GABA, gamma-aminobutyric acid; HDRS, Hamilton Depression Rating Scale; HNK, hydroxy-norketamine; HCN, hyperpolarization-activated cyclic nucleotide-gated; IV, intravenous; MDD, major depressive disorder; mTOR, mechanistic target of rapamycin; MADRS, Montgomery-Asberg Depression Rating Scale; NMDAR, N-methyl-D-aspartate receptor; RCT, randomized controlled trial.

\section{Disclosure}

The authors declare that there are no competing financial or non-financial interests in this work.

\section{References}

1. World Health Organization. Depression; 2018. Available from: https://www.who.int/news-room/fact-sheets/detail/depression. Accessed June 6, 2019

2. Ishak WW, Greenberg JM, Cohen RM. Predicting relapse in major depressive disorder using patient-reported outcomes of depressive symptom severity, functioning, and quality of life in the individual burden of illness index for depression (IBI-D). J Affect Disord. 2013;151:59-65. doi:10.1016/j.jad.2013.08.002

3. Collins PY, Patel V, Joestl SS, et al. Grand challenges in global mental health. Nature. 2011;475:27-30. doi:10.1038/475027a

4. Vandeleur CL, Fassassi S, Castelao E, et al. Prevalence and correlates of DSM-5 major depressive and related disorders in the community. Psychiatry Res. 2017;250:50-58. doi:10.1016/j. psychres.2017.01.060

5. Merikangas KR, Jin R, He J-P, et al. Prevalence and correlates of bipolar spectrum disorder in the world mental health survey initiative. Arch Gen Psychiatry. 2011;68:241-251. doi:10.1001/ archgenpsychiatry.2011.12

6. Judd LL, Akiskal HS, Schettler PJ, et al. The long-term natural history of the weekly symptomatic status of bipolar I disorder. Arch Gen Psychiatry. 2002;59:530-537. doi:10.1001/archpsyc.59.6.530

7. Judd LL, Akiskal HS. Depressive episodes and symptoms dominate the longitudinal course of bipolar disorder. Curr Psychiatry Rep. 2003;5:417-418. doi:10.1007/s11920-003-0077-2

8. Rong C, Park C, Rosenblat J, et al. Predictors of response to ketamine in treatment resistant major depressive disorder and bipolar disorder. Int $J$ Environ Res Public Health. 2018;15:771. doi:10.3390/ijerph15061188

9. Duman RS. A molecular and cellular theory of depression. Arch Gen Psychiatry. 1997;54:597-606. doi:10.1001/archpsyc.1997.018 30190015002

10. Trullas R, Skolnick P. Functional antagonists at the NMDA receptor complex exhibit antidepressant actions. Eur J Pharmacol. 1990;185:1-10. doi:10.1016/0014-2999(90)90204-J

11. Skolnick P, Popik P, Trullas R. Glutamate-based antidepressants: 20 years on. Trends Pharmacol Sci. 2009;30:563-569. doi:10.1016/ j.tips.2009.09.002

12. Skolnick P, Layer R, Popik P, Nowak G, Paul I, Trullas R. Adaptation of N-methyl-D-aspartate (NMDA) receptors following antidepressant treatment: implications for the pharmacotherapy of depression. Pharmacopsychiatry. 1996;29:23-26. doi:10.1055/s2007-979537

13. Lener MS, Niciu MJ, Ballard ED, et al. Glutamate and gammaaminobutyric acid systems in the pathophysiology of major depression and antidepressant response to ketamine. Biol Psychiatry. 2017;81:886-897. doi:10.1016/j.biopsych.2016.05.005
14. Murrough JW, Abdallah CG, Mathew SJ. Targeting glutamate signaling in depression: progress and prospects. Nat Rev Drug Discov. 2017;16:472-486. doi:10.1038/nrd.2017.16

15. Sanacora G, Mason GF, Rothman DL, Krystal JH. Increased occipital cortex GABA concentrations in depressed patients after therapy with selective serotonin reuptake inhibitors. Am J Psychiatry. 2002;159:663-665. doi:10.1176/appi.ajp.159.4.663

16. Grimm S, Luborzewski A, Schubert F, et al. Region-specific glutamate changes in patients with unipolar depression. $J$ Psychiatr Res. 2012;46:1059-1065. doi:10.1016/j.jpsychires.2012.04.018

17. Deutschenbaur L, Beck J, Kiyhankhadiv A, et al. Role of calcium, glutamate and NMDA in major depression and therapeutic application. Prog Neuropsychopharmacol Biol Psychiatry. 2016;64:325333. doi:10.1016/j.pnpbp.2015.02.015

18. Ignácio ZM, Réus GZ, Arent CO, Abelaira HM, Pitcher MR, Quevedo J. New perspectives on the involvement of mTOR in depression as well as in the action of antidepressant drugs: mTOR and depression. Br J Clin Pharmacol. 2016;82:12801290. doi:10.1111/bcp. 12975

19. Duman RS. Neurobiology of stress, depression, and rapid acting antidepressants: remodeling synaptic connections. Depress Anxiety. 2014;31:291-296. doi:10.1002/da.2014.31.issue-4

20. Oye I, Paulsen O, Maurset A. Effects of ketamine on sensory perception: evidence for a role of N-methyl-D-aspartate receptors. J Pharmacol Exp Ther. 1992;260:1209-1213.

21. Miller OH, Yang L, Wang C-C, et al. GluN2B-containing NMDA receptors regulate depression-like behavior and are critical for the rapid antidepressant actions of ketamine. eLife. 2014;3:e03581. doi:10.7554/eLife.03581

22. White PF, Ham J, Way WL, Trevor AJ. Pharmacology of ketamine isomers in surgical patients. Anesthesiology. 1980;52:231-239. doi:10.1097/00000542-198003000-00008

23. Yeung LY, Wai MSM, Fan M, et al. Hyperphosphorylated tau in the brains of mice and monkeys with long-term administration of ketamine. Toxicol Lett. 2010;193:189-193. doi:10.1016/j.toxlet.2010.01.008

24. Montgomery SA, Asberg M. A new depression scale designed to be sensitive to change. Br J Psychiatry J Ment Sci. 1979;134:382389. doi:10.1192/bjp.134.4.382

25. Hamilton M. A rating scale for depression. J Neurol Neurosurg Psychiatry. 1960;23:56-62. doi:10.1136/jnnp.23.1.56

26. Hamilton M. Development of a rating scale for primary depressive illness. Br J Soc Clin Psychol. 1967;6:278-296. doi:10.1111/ j.2044-8260.1967.tb00530.x

27. Beck AT, Ward CH, Mendelson M, Mock J, Erbaugh J. An inventory for measuring depression. Arch Gen Psychiatry. 1961;4:561571. doi:10.1001/archpsyc.1961.01710120031004

28. Furukawa TA, Fujita A, Harai H, Yoshimura R, Kitamura T, Takahashi K. Definitions of recovery and outcomes of major depression: results from a 10-year follow-up. Acta Psychiatr Scand. 2008;117:35-40.

29. Bandelow B, Baldwin DS, Dolberg OT, Andersen HF, Stein DJ. What is the threshold for symptomatic response and remission for major depressive disorder, panic disorder, social anxiety disorder, and generalized anxiety disorder? J Clin Psychiatry. 2006;67:14281434. doi:10.4088/JCP.v67n0914

30. McCloud TL, Caddy C, Jochim J, et al. Ketamine and other glutamate receptor modulators for depression in bipolar disorder in adults. Cochrane Database Syst Rev. 2015. doi:10.1002/ 14651858.CD011611.pub2

31. Caddy C, Amit BH, McCloud TL, et al. Ketamine and other glutamate receptor modulators for depression in adults. Cochrane Database Syst Rev. 2015. doi:10.1002/14651858.CD011612.pub2

32. Papadimitropoulou K, Vossen C, Karabis A, Donatti C, Kubitz N. Comparative efficacy and tolerability of pharmacological and somatic interventions in adult patients with treatment-resistant depression: a systematic review and network meta-analysis. Curr Med Res Opin. 2017;33:701-711. doi:10.1080/03007995.2017.1301903 
33. Romeo B, Choucha W, Fossati P, Rotge J-Y. Meta-analysis of short- and mid-term efficacy of ketamine in unipolar and bipolar depression. Psychiatry Res. 2015;230:682-688. doi:10.1016/j. psychres.2015.08.029

34. Caddy C, Giaroli G, White TP, Shergill SS, Tracy DK. Ketamine as the prototype glutamatergic antidepressant: pharmacodynamic actions, and a systematic review and meta-analysis of efficacy. Ther Adv Psychopharmacol. 2014;4:75-99. doi:10.1177/20451 25313507739

35. Kishimoto T, Chawla JM, Hagi K, et al. Single-dose infusion ketamine and non-ketamine N-methyl-D-aspartate receptor antagonists for unipolar and bipolar depression: a meta-analysis of efficacy, safety and time trajectories. Psychol Med. 2016;46:14591472. doi: $10.1017 / \mathrm{S} 0033291716000064$

36. Xu Y, Hackett M, Carter G, et al. Effects of low-dose and very lowdose ketamine among patients with major depression: a systematic review and meta-analysis. Int $J$ Neuropsychopharmacol. 2016;19: pyv124. doi:10.1093/ijnp/pyv124

37. Lee EE, Della Selva MP, Liu A, Himelhoch S. Ketamine as a novel treatment for major depressive disorder and bipolar depression: a systematic review and quantitative meta-analysis. Gen Hosp Psychiatry. 2015;37:178-184. doi:10.1016/j.genhosppsych.2015.01.003

38. McGirr A, Berlim MT, Bond DJ, Fleck MP, Yatham LN, Lam RW. A systematic review and meta-analysis of randomized, doubleblind, placebo-controlled trials of ketamine in the rapid treatment of major depressive episodes. Psychol Med. 2015;45:693-704. doi:10.1017/S0033291715001269

39. Ren L, Deng J, Min S, Peng L, Chen Q. Ketamine in electroconvulsive therapy for depressive disorder: a systematic review and meta-analysis. J Psychiatr Res. 2018;104:144-156. doi:10.1016/j. jpsychires.2018.07.003

40. McGirr A, Berlim MT, Bond DJ, Chan PY, Yatham LN, Lam RW. Adjunctive ketamine in electroconvulsive therapy: updated systematic review and meta-analysis. Br J Psychiatry. 2017;210:403407. doi:10.1192/bjp.bp.116.189993

41. Fond G, Bennabi D, Haffen E, et al. A bayesian framework systematic review and meta-analysis of anesthetic agents effectiveness/tolerability profile in electroconvulsive therapy for major depression. Sci Rep. 2016;6. doi:10.1038/srep19847

42. McGirr A, Berlim MT, Bond DJ, et al. A systematic review and metaanalysis of randomized controlled trials of adjunctive ketamine in electroconvulsive therapy: efficacy and tolerability. J Psychiatr Res. 2015;62:23-30. doi:10.1016/j.jpsychires.2015.01.003

43. Coyle CM, Laws KR. The use of ketamine as an antidepressant: a systematic review and meta-analysis: ketamine as an antidepressant. Hum Psychopharmacol Clin Exp. 2015;30:152-163. doi:10.1002/hup.v30.3

44. Newport DJ, Carpenter LL, McDonald WM, Potash JB, Tohen M, Nemeroff CB; APA Council of Research Task Force on Novel Biomarkers and Treatments.. Ketamine and other NMDA antagonists: early clinical trials and possible mechanisms in depression. $\mathrm{Am} \mathrm{J}$ Psychiatry. 2015;172:950-966. doi:10.1176/appi.ajp.2015.15010055

45. Fond G, Loundou A, Rabu C, et al. Ketamine administration in depressive disorders: a systematic review and meta-analysis. Psychopharmacology (Berl). 2014;231:3663-3676. doi:10.1007/ s00213-014-3664-5

46. Ionescu DF, Bentley KH, Eikermann M, et al. Repeat-dose ketamine augmentation for treatment-resistant depression with chronic suicidal ideation: a randomized, double blind, placebo controlled trial. J Affect Disord. 2019;243:516-524. doi:10.1016/j.jad.2018. 09.037

47. Popova V, Daly EJ, Trivedi M, et al. Efficacy and safety of flexibly dosed esketamine nasal spray combined with a newly initiated oral antidepressant in treatment-resistant depression: a randomized double-blind active-controlled study. Am J Psychiatry. 2019;176:428438. doi:10.1176/appi.ajp.2019.19020172
48. Arabzadeh S, Hakkikazazi E, Shahmansouri N, et al. Does oral administration of ketamine accelerate response to treatment in major depressive disorder? Results of a double-blind controlled trial. $J$ Affect Disord. 2018;235:236-241. doi:10.1016/j.jad.2018.02.056

49. Canuso CM, Singh JB, Fedgchin M, et al. Efficacy and safety of intranasal esketamine for the rapid reduction of symptoms of depression and suicidality in patients at imminent risk for suicide: results of a double-blind, randomized, placebo-controlled study. Am J Psychiatry. 2018;175:620-630. doi:10.1176/appi.ajp.2018.17060720

50. Daly EJ, Singh JB, Fedgchin M, et al. Efficacy and safety of intranasal esketamine adjunctive to oral antidepressant therapy in treatmentresistant depression: a randomized clinical trial. JAMA Psychiatry. 2018;75:139-148. doi:10.1001/jamapsychiatry.2017.3739

51. Domany Y, Bleich-Cohen M, Tarrasch R, et al. Repeated oral ketamine for out-patient treatment of resistant depression: randomized, double-blind, placebo-controlled, proof-of-concept study. Br J Psychiatry. 2018;214:20-26. doi:10.1192/bjp.2018.196

52. Chen M-H, Li C-T, Lin W-C, et al. Persistent antidepressant effect of low-dose ketamine and activation in the supplementary motor area and anterior cingulate cortex in treatment-resistant depression: a randomized control study. $J$ Affect Disord. 2018;225:709-714. doi:10.1016/j.jad.2017.09.008

53. Su T-P, Chen M-H, Li C-T, et al. Dose-related effects of adjunctive ketamine in Taiwanese patients with treatment-resistant depression. Neuropsychopharmacology. 2017;42:2482-2492. doi:10.1038/ npp.2017.94

54. Hu Y-D, Xiang Y-T, Fang J-X, et al. Single i.v. ketamine augmentation of newly initiated escitalopram for major depression: results from a randomized, placebo-controlled 4-week study. Psychol Med. 2016;46:623-635. doi:10.1017/S0033291715002159

55. Li C-T, Chen M-H, Lin W-C, et al. The effects of low-dose ketamine on the prefrontal cortex and amygdala in treatment-resistant depression: a randomized controlled study: ketamine modulates the PFC. Hum Brain Mapp. 2016;37:1080-1090. doi:10.1002/hbm.23085

56. Singh JB, Fedgchin M, Daly E, et al. Intravenous esketamine in adult treatment-resistant depression: a double-blind, double-randomization, placebo-controlled study. Biol Psychiatry. 2016;80:424431. doi:10.1016/j.biopsych.2015.10.018

57. Carspecken CW, Borisovskaya A, Lan ST, et al. Ketamine anesthesia does not improve depression scores in electroconvulsive therapy: a randomized clinical trial. $J$ Neurosurg Anesthesiol. 2018;30:305-313.

58. Gamble JJ, Bi H, Bowen R, et al. Ketamine-based anesthesia improves electroconvulsive therapy outcomes: a randomized-controlled study. Can J Anesth Can Anesth. 2018;65:636-646. doi:10.1007/s12630-018-1088-0

59. Price RB, Nock MK, Charney DS, Mathew SJ. Effects of intravenous ketamine on explicit and implicit measures of suicidality in treatment-resistant depression. Biol Psychiatry. 2009;66:522-526. doi:10.1016/j.biopsych.2009.04.029

60. Price RB, Iosifescu DV, Murrough JW, et al. Effects of ketamine on explicit and implicit suicidal cognition: a randomized controlled trial in treatment-resistant depression: effects of ketamine on suicidality. Depress Anxiety. 2014;31:335-343. doi:10.1002/da.2014. 31.issue-4

61. Murrough JW, Soleimani L, DeWilde KE, et al. Ketamine for rapid reduction of suicidal ideation: a randomized controlled trial. Psychol Med. 2015;45:3571-3580. doi:10.1017/S0033291715001269

62. Ionescu DF, Luckenbaugh DA, Niciu MJ, Richards EM, Zarate CA. A single infusion of ketamine improves depression scores in patients with anxious bipolar depression. Bipolar Disord. 2015;17:438-443. doi:10.1111/bdi.2015.17.issue-4

63. Singh JB, Fedgchin M, Daly EJ, et al. A double-blind, randomized, placebo-controlled, dose-frequency study of intravenous ketamine in patients with treatment-resistant depression. Am J Psychiatry. 2016;173:816-826. doi:10.1176/appi.ajp.2016.16010037 
64. Ghasemi M, Kazemi MH, Yoosefi A, et al. Rapid antidepressant effects of repeated doses of ketamine compared with electroconvulsive therapy in hospitalized patients with major depressive disorder. Psychiatry Res. 2014;215:355-361. doi:10.1016/j.psychres.2013.12.008

65. Grant IS, Nimmo WS, Clements JA. Pharmacokinetics and analgesic effects of i.m. and oral ketamine. Br J Anaesth. 1981;53:805810. doi:10.1093/bja/53.8.805

66. Clements JA, Nimmo WS, Grant IS. Bioavailability, pharmacokinetics, and analgesic activity of ketamine in humans. J Pharm Sci. 1982;71:539-542. doi:10.1002/jps.2600710516

67. Yanagihara Y, Ohtani M, Kariya S, et al. Plasma concentration profiles of ketamine and norketamine after administration of various ketamine preparations to healthy Japanese volunteers. Biopharm Drug Dispos. 2003;24:37-43. doi:10.1002/(ISSN)1099$081 \mathrm{X}$

68. Lapidus KAB, Levitch CF, Perez AM, et al. A randomized controlled trial of intranasal ketamine in major depressive disorder Biol Psychiatry. 2014;76:970-976. doi:10.1016/j.biopsych.2014.03. 026

69. Domino EF, Chodoff P, Corssen G. Pharmacologic effects of CI581, a new dissociative anesthetic, in man. Clin Pharmacol Ther. 1965;6:279-291. doi:10.1002/cpt196563279

70. Hashimoto K, Sawa A, Iyo M. Increased levels of glutamate in brains from patients with mood disorders. Biol Psychiatry. 2007;62:1310-1316. doi:10.1016/j.biopsych.2006.09.037

71. Choudary PV, Molnar M, Evans SJ, et al. Altered cortical glutamatergic and GABAergic signal transmission with glial involvement in depression. Proc Natl Acad Sci USA. 2005;102:1565315658. doi:10.1073/pnas.0507901102

72. Zanos P, Moaddel R, Morris PJ, et al. Ketamine and ketamine metabolite pharmacology: insights into therapeutic mechanisms. Pharmacol Rev. 2018;70:621-660. doi:10.1124/pr.117.01 5198

73. Abdallah CG, Sanacora G, Duman RS, Krystal JH. Ketamine and rapid-acting antidepressants: a window into a new neurobiology for mood disorder therapeutics. Аnnu Rev Med. 2015;66:509-523. doi:10.1146/annurev-med-053013-062946

74. Yamanaka H, Yokoyama C, Mizuma H, et al. A possible mechanism of the nucleus accumbens and ventral pallidum 5-HT1B receptors underlying the antidepressant action of ketamine: a PET study with macaques. Transl Psychiatry. 2014;4:e342. doi:10.1038/ tp. 2013.112

75. Yamamoto S, Ohba H, Nishiyama S, et al. Subanesthetic doses of ketamine transiently decrease serotonin transporter activity: a PET study in conscious monkeys. Neuropsychopharmacol Off Publ Am Coll Neuropsychopharmacol. 2013;38:2666-2674. doi:10.1038/ npp.2013.176

76. Pham TH, Mendez-David I, Defaix C, et al. Ketamine treatment involves medial prefrontal cortex serotonin to induce a rapid antidepressant-like activity in BALB/cJ mice. Neuropharmacology. 2017;112:198-209. doi:10.1016/j.neuropharm.2016.05.010

77. Du Jardin KG, Müller HK, Elfving B, Dale E, Wegener G, Sanchez C. Potential involvement of serotonergic signaling in ketamine's antidepressant actions: a critical review. Prog Neuropsychopharmacol Biol Psychiatry. 2016;71:27-38. doi:10.1016/j.pnpbp.2016.05.007

78. Zanos P, Moaddel R, Morris PJ, et al. NMDAR inhibition-independent antidepressant actions of ketamine metabolites. Nature. 2016;533:481-486. doi:10.1038/nature17998

79. Philip NS, Carpenter LL, Tyrka AR, Price LH. Nicotinic acetylcholine receptors and depression: a review of the preclinical and clinical literature. Psychopharmacology (Berl). 2010;212:1-12. doi:10.1007/s00213-010-1932-6

80. Hustveit O, Maurset A, Oye I. Interaction of the chiral forms of ketamine with opioid, phencyclidine, sigma and muscarinic receptors. Pharmacol Toxicol. 1995;77:355-359. doi:10.1111/j.16000773.1995.tb01041.x
81. Lewis AS, Vaidya SP, Blaiss CA, et al. Deletion of the hyperpolarization-activated cyclic nucleotide-gated channel auxiliary subunit TRIP8b impairs hippocampal Ih localization and function and promotes antidepressant behavior in mice. J Neurosci Off J Soc Neurosci. 2011;31:7424-7440. doi:10.1523/JNEUROSCI.0936-11.2011

82. Williams NR, Heifets BD, Blasey C, et al. Attenuation of antidepressant effects of ketamine by opioid receptor antagonism. Am J Psychiatry. 2018;175:1205-1215. doi:10.1176/appi.ajp.2018.1802 0138

83. Zhang K, Hashimoto K. Lack of opioid system in the antidepressant actions of ketamine. Biol Psychiatry. 2019;85:e25-e27. doi:10.1016/j.biopsych.2018.11.006

84. Yoon G, Petrakis IL, Krystal JH. Association of combined naltrexone and ketamine with depressive symptoms in a case series of patients with depression and alcohol use disorder. JAMA Psychiatry. 2019. doi:10.1001/jamapsychiatry.2018.3990

85. Sinner B, Graf BM. Ketamine. Handb Exp Pharmacol. 2008;313333. doi:10.1007/978-3-540-74806-9_15

86. Zhang J-C, Li S-X, Hashimoto KR. (-)-ketamine shows greater potency and longer lasting antidepressant effects than S (+)-ketamine. Pharmacol Biochem Behav. 2014;116:137-141. doi:10.1016/ j.pbb.2013.11.033

87. Fukumoto K, Toki H, Iijima M, et al. Antidepressant potential of (R)-ketamine in rodent models: comparison with (S)-ketamine. $J$ Pharmacol Exp Ther. 2017;361:9-16. doi:10.1124/jpet.116.239228

88. Yang C, Shirayama Y, Zhang J-C, et al. R-ketamine: a rapid-onset and sustained antidepressant without psychotomimetic side effects. Transl Psychiatry. 2015;5:e632. doi:10.1038/tp.2015.136

89. Hashimoto K. Rapid-acting antidepressant ketamine, its metabolites and other candidates: a historical overview and future perspective. Psychiatry Clin Neurosci. 2019. doi:10.1111/pcn.12902

90. Zarate CA, Brutsche N, Laje G, et al. Relationship of ketamine's plasma metabolites with response, diagnosis, and side effects in major depression. Biol Psychiatry. 2012;72:331-338. doi:10.1016/j. biopsych.2012.03.004

91. Persson J, Hasselström J, Maurset A, et al. Pharmacokinetics and non-analgesic effects of S- and R-ketamines in healthy volunteers with normal and reduced metabolic capacity. Eur $J$ Clin Pharmacol. 2002;57:869-875. doi:10.1007/s002280100353

92. Hijazi Y, Boulieu R. Contribution of CYP3A4, CYP2B6, and CYP2C9 isoforms to N-demethylation of ketamine in human liver microsomes. Drug Metab Dispos. 2002;30:853-858. doi:10.1124/ dmd.30.7.853

93. Yanagihara Y, Kariya S, Ohtani M, et al. Involvement of CYP2B6 in N-demethylation of ketamine in human liver microsomes. Drug Metab Dispos. 2001;29:887-890.

94. Adams JD, Baillie TA, Trevor AJ, Castagnoli N. Studies on the biotransformation of ketamine. 1-identification of metabolites produced in vitro from rat liver microsomal preparations. Biomed Mass Spectrom. 1981;8:527-538. doi:10.1002/bms.1200081103

95. Desta Z, Moaddel R, Ogburn ET, et al. Stereoselective and regiospecific hydroxylation of ketamine and norketamine. Xenobiotica. 2012;42:1076-1087. doi:10.3109/00498254.2012.685777

96. Moaddel R, Venkata SL, Tanga MJ, et al. A parallel chiral-achiral liquid chromatographic method for the determination of the stereoisomers of ketamine and ketamine metabolites in the plasma and urine of patients with complex regional pain syndrome. Talanta. 2010;82:1892-1904. doi:10.1016/j.talanta.2010.06.023

97. Blier P, Zigman D, Blier J. On the safety and benefits of repeated intravenous injections of ketamine for depression. Biol Psychiatry. 2012;72:e11-e12. doi:10.1016/j.biopsych.2012.02. 039

98. Pickering G, Pereira B, Morel V, et al. Rationale and design of a multicenter randomized clinical trial with memantine and dextromethorphan in ketamine-responder patients. Contemp Clin Trials. 2014;38:314-320. doi:10.1016/j.cct.2014.06.004 
99. Husain SS, Kevan IM, Linnell R, Scott AIF. Electroconvulsive therapy in depressive illness that has not responded to drug treatment. J Affect Disord. 2004;83:121-126. doi:10.1016/j.jad.2004. 05.006

100. Price RB, Mathew SJ. Does ketamine have anti-suicidal properties? Current status and future directions. CNS Drugs. 2015;29:181-188. doi:10.1007/s40263-015-0232-4

101. DiazGranados N, Ibrahim LA, Brutsche NE, et al. Rapid resolution of suicidal ideation after a single infusion of an N-methyl-D-aspartate antagonist in patients with treatment-resistant major depressive disorder. J Clin Psychiatry. 2010;71:1605-1611. doi:10.4088/ JCP.09m05327blu

102. Zarate CA, Brutsche NE, Ibrahim L, et al. Replication of ketamine's antidepressant efficacy in bipolar depression: a randomized controlled add-on trial. Biol Psychiatry. 2012;71:939-946. doi:10.1016/j.biopsych.2011.12.010

103. Ballard ED, Luckenbaugh DA, Richards EM, et al. Assessing measures of suicidal ideation in clinical trials with a rapid-acting antidepressant. J Psychiatr Res. 2015;68:68-73. doi:10.1016/j. jpsychires.2015.06.003

104. Erhardt S, Lim CK, Linderholm KR, et al. Connecting inflammation with glutamate agonism in suicidality. Neuropsychopharmacol Off Publ Am Coll Neuropsychopharmacol. 2013;38:743-752. doi:10.1038/npp.2012.248

105. Zhu W, Ding Z, Zhang Y, Shi J, Hashimoto K, Lu L. Risks associated with misuse of ketamine as a rapid-acting antidepressant. Neurosci Bull. 2016;32:557-564. doi:10.1007/s12264-0160081-2

106. Short B, Fong J, Galvez V, Shelker W, Loo CK. Side-effects associated with ketamine use in depression: a systematic review. Lancet Psychiatry. 2018;5:65-78. doi:10.1016/S2215-0366(17) 30272-9

107. Orhurhu VJ, Claus LE, Cohen SP. Ketamine Toxicity. In StatPearls. StatPearls Publishing; 2019.

108. Diazgranados N, Ibrahim L, Brutsche NE, et al. A randomized addon trial of an N-methyl-D-aspartate antagonist in treatment-resistant bipolar depression. Arch Gen Psychiatry. 2010;67:793. doi:10.1001/archgenpsychiatry.2010.90

109. Sos P, Klirova M, Novak T, Kohutova B, Horacek J, Palenicek T. Relationship of ketamine's antidepressant and psychotomimetic effects in unipolar depression. Neuroendocrinol Lett. 2013;55 (7):287-293.

110. Zarate CA, Singh JB, Carlson PJ, et al. A randomized trial of an Nmethyl-D-aspartate antagonist in treatment-resistant major depression. Arch Gen Psychiatry. 2006;63:9. doi:10.1001/archpsyc.63. 8.856

111. Berman RM, Cappiello A, Anand A, et al. Antidepressant effects of ketamine in depressed patients. Biol Psychiatry. 2000;47:351-354. doi:10.1016/S0006-3223(99)00230-9

112. Valentine GW, Mason GF, Gomez R, et al. The antidepressant effect of ketamine is not associated with changes in occipital amino acid neurotransmitter content as measured by [1H]-MRS. Psychiatry Res. Neuroimaging. 2011;191:122-127. doi:10.1016/j. pscychresns.2010.10.009

113. Murrough JW, Iosifescu DV, Chang LC, et al. Antidepressant efficacy of ketamine in treatment-resistant major depression: a two-site randomized controlled trial. $\mathrm{Am} J$ Psychiatry. 2013;170:1134-1142. doi:10.1176/appi.ajp.2013.13030392

114. Lai R, Katalinic N, Glue P, et al. Pilot dose-response trial of i.v. ketamine in treatment-resistant depression. World J Biol Psychiatry. 2014;15:579-584. doi:10.3109/15622975.2014.922697

115. Järventausta K, Chrapek W, Kampman O, et al. Effects of Sketamine as an anesthetic adjuvant to propofol on treatment response to electroconvulsive therapy in treatment-resistant depression: a randomized pilot study. $J$ Ect. 2013;29:158-161. doi:10.1097/YCT.0b013e318283b7e9
116. Yoosefi A, Sepehri AS, Kargar M, et al. Comparing effects of ketamine and thiopental administration during electroconvulsive therapy in patients with major depressive disorder: a randomized, double-blind study. J Ect. 2014;30:15-21. doi:10.1097/YCT.0b013e3182a4b4c6

117. Loo CK, Katalinic N, Garfield JBB, Sainsbury K, Hadzi-Pavlovic D, Mac-Pherson R. Neuropsychological and mood effects of ketamine in electroconvulsive therapy: a randomised controlled trial. $J$ Affect Disord. 2012;142:233-240. doi:10.1016/j.jad.2012.04.032

118. Abdallah CG, Fasula M, Kelmendi B, Sanacora G, Ostroff R. Rapid antidepressant effect of ketamine in the electroconvulsive therapy setting. $J$ Ect. 2012;28:157-161. doi:10.1097/YCT.0b013e31824f8296

119. Wang X, Chen Y, Zhou X, Liu F, Zhang T, Zhang C. Effects of propofol and ketamine as combined anesthesia for electroconvulsive therapy in patients with depressive disorder. $J$ Ect. 2012;28:128-132. doi:10.1097/YCT.0b013e31823fbb13

120. Rybakowski JK, Permoda-Osip A, Skibinska M, Adamski R, Bartkowska-Sniatkowska A. Single ketamine infusion in bipolar depression resistant to antidepressants: are neurotrophins involved? Hum Psychopharmacol Clin Exp. 2013;28:87-90. doi:10.1002/hup. v28.1

121. Rasmussen KG, Kung S, Lapid MI, et al. A randomized comparison of ketamine versus methohexital anesthesia in electroconvulsive therapy. Psychiatry Res. 2014;215:362-365. doi:10.1016/j. psychres.2013.12.027

122. Shams Alizadeh N, Maroufi A, Nasseri K, et al. Antidepressant effect of combined ketamine and electroconvulsive therapy on patients with major depressive disorder: a randomized trial. Iran $J$ Psychiatry Behav Sci. 2015;9:e1578. doi:10.17795/ijpbs

123. Salehi B, Mohammadbeigi A, Kamali A, Taheri-Nejad M, Moshiri I. Impact comparison of ketamine and sodium thiopental on anesthesia during electroconvulsive therapy in major depression patients with drug-resistant; a double-blind randomized clinical trial. Ann Card Anaesth. 2015;18:486-490. doi:10.4103/0971-9784.166444

124. Ozkan Kuscu O, Karacaer F, Biricik E, Gulec E, Tamam L, Gunes Y. Effect of ketamine, thiopental and ketamine-thiopental combination during electroconvulsive therapy for depression. Turk $J$ Anesth Reanim. 2015;43:313-317. doi:10.5152/TJAR.

125. Zhong $\mathrm{X}, \mathrm{He} \mathrm{H}$, Zhang $\mathrm{C}$, et al. Mood and neuropsychological effects of different doses of ketamine in electroconvulsive therapy for treatment-resistant depression. J Affect Disord. 2016;201:124130. doi:10.1016/j.jad.2016.05.011

126. Zhang M, Rosenheck R, Lin X, et al. A randomized clinical trial of adjunctive ketamine anesthesia in electro-convulsive therapy for depression. J Affect Disord. 2018;227:372-378. doi:10.1016/j. jad.2017.11.034

127. Ray-Griffith SL, Eads LA, Han X, Golden K, Stowe ZN. A randomized pilot study comparing ketamine and methohexital anesthesia for electroconvulsive therapy in patients with depression. $J$ Ect. 2017;33:268-271. doi:10.1097/YCT.0000000000000406

128. Fernie G, Currie J, Perrin JS, et al. Ketamine as the anaesthetic for electroconvulsive therapy: the KANECT randomised controlled trial. Br J Psychiatry J Ment Sci. 2017;210:422-428. doi:10.1192/ bjp.bp.116.189134

129. Chen Q, Min S, Hao X, et al. Effect of low dose of ketamine on learning memory function in patients undergoing electroconvulsive therapy-a randomized, double-blind, controlled clinical study. $J$ Ect. 2017;33:89-95. doi:10.1097/YCT.0000000000000406

130. Anderson IM, Blamire A, Branton T, et al. Ketamine augmentation of electroconvulsive therapy to improve neuropsychological and clinical outcomes in depression (Ketamine-ECT): a multicentre, double-blind, randomised, parallel-group, superiority trial. Lancet Psychiatry. 2017;4:365-377. doi:10.1016/S2215-0366(17)30077-9

131. Anderson IM, Blamire A, Branton T, et al. Randomised Controlled Trial of Ketamine Augmentation of Electroconvulsive Therapy to Improve Neuropsychological and Clinical Outcomes in Depression (ketamine-ect Study). NIHR Journals Library; 2017. 
132. Salvadore G, Cornwell BR, Colon-Rosario V, et al. Increased anterior cingulate cortical activity in response to fearful faces: a neurophysiological biomarker that predicts rapid antidepressant response to ketamine. Biol Psychiatry. 2009;65:289-295. doi:10.1016/j.biopsych.2008.08.014

133. Mathew SJ, Murrough JW, Aan Het Rot M, Collins KA, Reich DL, Charney DS. Riluzole for relapse prevention following intravenous ketamine in treatment-resistant depression: a pilot randomized, placebo-controlled continuation trial. Int J Neuropsychopharmacol. 2010;13:71-82. doi:10.1017/S1461145709000169

134. Salvadore G, Cornwell BR, Sambataro F, et al. Anterior cingulate desynchronization and functional connectivity with the amygdala during a working memory task predict rapid antidepressant response to ketamine. Neuropsychopharmacology. 2010;35:14151422. doi:10.1038/npp.2010.24

135. aan het Rot M, Collins KA, Murrough JW, et al. Safety and efficacy of repeated-dose intravenous ketamine for treatment-resistant depression. Biol Psychiatry. 2010;67:139-145. doi:10.1016/j. biopsych.2009.08.038

136. Permoda-Osip A, Adamski R, Bartkowska-Sniatkowska A, Chlopocka-Wozniak M, Skibinska M, Rybakowski JK. P.2.e.019 Efficacy of single ketamine infusion in bipolar depression: relationship with serum BDNF. Eur Neuropsychopharmacol. 2011;21: S428-S429. doi:10.1016/S0924-977X(11)70692-7
137. Larkin GL, Beautrais AL. A preliminary naturalistic study of lowdose ketamine for depression and suicide ideation in the emergency department. Int J Neuropsychopharmacol. 2011;14:1127-1131. doi:10.1017/S1461145711000629

138. Ibrahim L, Diazgranados N, Luckenbaugh DA, et al. Rapid decrease in depressive symptoms with an N-methyl-D-aspartate antagonist in ECT-resistant major depression. Prog Neuropsychopharmacol Biol Psychiatry. 2011;35:1155-1159. doi:10.1016/j.pnpbp.2011.03.019

139. Thakurta RG, Ray P, Das R, Thakurta R, Kanji D, Bisui B. Rapid antidepressant response with ketamine: is it the solution to resistant depression? Indian J Psychol Med. 2012;34:56-60. doi:10.4103/ 0253-7176.96161

140. Salvadore G, van der Veen JW, Zhang Y, et al. An investigation of amino-acid neurotransmitters as potential predictors of clinical improvement to ketamine in depression. Int $J$ Neuropsychopharmacol. 2012;15:1063-1072. doi:10.1017/S1461145711001593

141. Carlson PJ, Diazgranados N, Nugent AC, et al. Neural correlates of rapid antidepressant response to ketamine in treatment-resistant unipolar depression: a preliminary positron emission tomography study. Biol Psychiatry. 2013;73:1213-1221. doi:10.1016/j.biopsych.2013.02.008

142. Kudoh A, Takahira Y, Katagai H, Takazawa T. Small-dose ketamine improves the postoperative state of depressed patients. Anesth Analg. 2002;95:114-118. table of contents. doi:10.1097/00000539200212000-00031
Drug Design, Development and Therapy

\section{Publish your work in this journal}

Drug Design, Development and Therapy is an international, peerreviewed open-access journal that spans the spectrum of drug design and development through to clinical applications. Clinical outcomes, patient safety, and programs for the development and effective, safe, and sustained use of medicines are a feature of the journal, which has also

\section{Dovepress}

been accepted for indexing on PubMed Central. The manuscript management system is completely online and includes a very quick and fair peer-review system, which is all easy to use. Visit http://www. dovepress.com/testimonials.php to read real quotes from published authors. 